\title{
OUTCOME OF PREGNANCIES HAVING BLEEDING PERVAGINA IN THE FIRST TRIMESTER
}

\author{
Sukhamoy Barik1, Saima Javed ${ }^{2}$, Sajal Datta 3 , Bijit Chowdhury4, Papia Datta ${ }^{5}$ \\ ${ }^{1}$ Deputy Visiting Surgeon, Department of Obstetrics and Gynaecology, Sishumangal Hospital, Kolkata. \\ ${ }^{2}$ Senior Resident, Department of Obstetrics and Gynaecology, Nilratan Sirkar Medical College Hospital, Kolkata. \\ 3 Professor, Department of Obstetrics and Gynaecology, Sishumangal Hospital, Kolkata. \\ 4 Professor and HOD, Department of Obstetrics and Gynaecology, Sishumangal Hospital, Kolkata. \\ 5Medical Officer, ESI Hospital, Kolkata.
}

\section{ABSTRACT}

\section{BACKGROUND}

Vaginal bleeding in early weeks being one of the frequent occurrence, about $20-25 \%$ of all pregnancies and have a lot of attention during the last few decades as a predictor of subsequent foetal outcome. In those pregnancies which continue, there is increased incidence of later problems including preterm labour/delivery, Low Birth Weight (LBW), gestational hypertension/Pregnancy Induced Hypertension (PIH), Intrauterine Foetal Death (IUFD), etc.

\section{AIMS}

To evaluate the pregnancy outcome (Both maternal and foetal) among groups of patients having bleeding per vagina in the first trimester.

\section{SETTING}

Tertiary level hospital.

\section{STUDY DESIGN}

A hospital-based observational comparative study.

\section{METHOD AND MATERIAL}

In this study, total 200 patients (100 in study group and 100 in control group) were taken from September 2009 to August 2010. Out of this 200, 6 patients in study group and 5 patients in control group lost during followup. So, finally 94 patients in study group and 95 patients in control group were critically compared.

\section{RESULT}

In this study mothers who had history of bleeding in $1^{\text {st }}$ trimester, $28.72 \%$ had miscarriage, whereas in control group it was $11.57 \% .65 .95 \%$ of women who bleed in 1 st trimester continued their pregnancy beyond 28 weeks, which is statistically significant when compared with control group. Incidence of APH (13.82\%) was also found statistically significant. 15.95\% babies were found suffering from IUGR when compared with control group, which was $7.36 \%$. Incidence of vaginal delivery in study group was significantly less when compared with control group. We also found that women who bleed in 1 st trimester $3.19 \%$ turn out to be ectopic pregnancy, $2.12 \%$ were molar pregnancy. No significance was noted in the study group in respect to placenta previa, PROM, $\mathrm{PIH}, \mathrm{CS}$ delivery. The neonatal morbidity and mortality were also found not significant when compared to control group.

\section{CONCLUSION}

Pregnancies continuing following vaginal bleeding in the first trimester should be grouped as a high risk pregnancy, because of various complications to the mother as well as to the growing embryo or foetus.

\section{KEYWORDS}

$1^{\text {st }}$ trimester, Bleeding Pervagina, Pregnancy Outcome.

HOW TO CITE THIS ARTICLE: Barik S, Javed S, Datta S, et al. Outcome of pregnancies having bleeding pervagina in the first trimester. J. Evolution Med. Dent. Sci. 2016;5(55):3750-3755, DOI: 10.14260/jemds/2016/859

\section{INTRODUCTION}

Bleeding pervagina in first trimester or in early weeks of pregnancy is a very common complaint of mothers in our dayto-day practice.

Financial or Other, Competing Interest: None.

Submission 26-05-2016, Peer Review 28-06-2016,

Acceptance 04-07-2016, Published 09-07-2016.

Corresponding Author:

Dr. Sukhamoy Barik,

Basundhara Apartment,

A Block, Flat No. 3,

9 MC Garden Road,

Kolkata-700030, West Bengal.

E-mail:sukhamoy83@gmail.com

DOI: $10.14260 /$ jemds $/ 2016 / 859$
This not only causes anxiety for the couple, but also troublesome for the treating doctor. If we know the possible complications and their incidences in such complicated pregnancies, it will be easier for us to counsel and to manage and treat the patient properly.

Early weeks (4-12 weeks) pregnancy is the period of organogenesis. Various factors may disturb the pregnancy during this period, which has subsequent effect on obstetric outcome. About $20-30 \%$ of pregnancies are lost during early weeks. Because of greater concern about the foetal well-being, early weeks of pregnancy has gained considerable importance. Patients with vaginal bleeding, light or heavy were more likely to experience spontaneous loss before 24 weeks of gestation [odds ratio (OR) 2.5 and 4.2 respectively] and caesarean 
delivery (OR 1.1 and 1.4 respectively). Light bleeding subjects were more likely to have pre-eclampsia (OR 1.5), preterm delivery (OR 1.3) and placental abruption (OR 1.6). Heavy vaginal bleeding subjects were more likely to have intrauterine growth restriction (OR 2.6), preterm delivery (OR 3), preterm premature rupture of membranes (OR 3.2) and placental abruption (OR 3.6). First trimester vaginal bleeding is an independent risk factor for adverse obstetric outcome that is directly proportional to the amount of bleeding. ${ }^{1}$

Primigravida and women with previous live births have a lower risk of miscarriage. The risk of miscarriage increases cumulatively according to the number of previous miscarriages. ${ }^{2}$ Similarly, woman with previous ectopic pregnancy are at substantially increased risk of another ectopic pregnancy. 3 There is approximately a ten-fold increased risk of another hydatidiform mole in women with history of an affected pregnancy. 4

Women with threatened miscarriage were more likely to have antepartum haemorrhage of unknown origin (OR 1.83). Elective caesarean section (OR 1.30) and manual removal of placenta (OR 1.40) were performed more frequently in these women, who also have a risk of preterm delivery (OR 1.56) and malpresentation (OR 1.26). Pregnancies complicated by threatened miscarriages are at a slightly higher risk of obstetric complications and interventions. 5

\section{METHODS}

This is a hospital-based observational comparative study, was conducted at Ramakrishna Mission Seva Pratishthan, Kolkata, between September 2009 and August 2010. All antenatal mothers attending various units of Department of Obstetrics and Gynaecology, are the population under study. This study was conducted on 200 patients (Including OPD and indoor patients). Out of these 200 patients, 100 patients were in study group and 100 patients were in control group. Out of 100 patients in study group, 6 cases were lost in followup. So, finally 94 cases were in study group $(\mathrm{n}=94) ; 5$ cases in control group were lost in followup. So, finally 95 cases were in pregnancy outcome (both maternal and foetal) were critically compared in between the study and control group.

\section{Inclusion Criteria: For Study Group}

Primigravida mothers with history of amenorrhoea of less than or equal to 12 weeks with history of regular cycles and no history of intake of OCP in recent past with bleeding per vagina and positive urine for pregnancy test.

\section{For Control Group}

Primigravida mothers with history of amenorrhoea of more than 12 weeks with history of regular cycles and no history of intake of oral contraceptive pill in recent past with no history of bleeding per vagina in first trimester and positive urine for pregnancy test.

\section{Exclusion Criteria}

Patients less than 18 years or more than 30 years old, USG proved multifoetal pregnancy, Patients with bleeding diathesis, Patients are on anticoagulant therapy, Patients with history of known Medical/Endocrinal cause of miscarriage, Patients with history of known gynaecological/local cause of bleeding, Patients with history of any addiction.
Patients attending the outpatient department or emergency with "SELF REPORTED SYMPTOMS" of bleeding pervagina in first trimester. All these cases in the study group were first admitted and then were followed up in the antenatal clinic and re-admitted as and when required. Patients in control group were followed up in antenatal clinic and admitted whenever necessary; 28 weeks of gestation was the cut-off point for considering period of viability in our study.

\section{Follow Up}

Patients were followed up in a regular and practical manner during the course of the study. Patients were re-admitted when needed and managed as far as practicable; 25 cases were readmitted due to recurrent bleeding episodes, 15 cases with severe IUGR and 8 cases with PIH were readmitted in between 32-36 weeks. Patients were followed up throughout second and third trimester, to detect any pregnancy complications like preterm labour, IUGR, APH, PIH, etc.

All other patients were admitted in between 38-40 weeks for close monitoring and for making plan of delivery.

Mode of delivery was individualized. Patients with moderate-to-severe IUGR, placenta previa and some case of PIH were delivered by elective caesarean section. Large number of patients went into spontaneous labour; others were induced for labour. Among these some required emergency caesarean section in first stage of labour due to foetal distress. Some required forceps delivery due to foetal distress in second stage of labour. Third and fourth stage of labour were observed carefully, to detect retained placenta, $\mathrm{PPH}$ and postpartum eclampsia, especially in cases with history of $\mathrm{APH}, \mathrm{PIH}$, pre-eclampsia.

\section{Ethics}

This study was approved by the Ethical Committee of this Institution. Written consent was taken from each patient under this study.

\section{STATISTICS}

After collecting all the data of both the groups (study and control), we have calculated the comparative incidence and statistical significance of different types of outcome by Chi Square $\left(\mathrm{X}^{2}\right)$ test.

\section{RESULT}

In this study, total number of population in study groups was $94(\mathrm{n}=94)$ and number of population in control group was 95 $(\mathrm{n}=95)$.

In our study the incidence of ectopic pregnancy (Table 1) and Molar pregnancy (Table 2) were higher in study groups, compared to control groups.

\begin{tabular}{|c|c|c|c|c|}
\hline & Ectopic & $\begin{array}{c}\text { Non- } \\
\text { Ectopic }\end{array}$ & $\begin{array}{c}\text { Incidence } \\
\text { (\%) }\end{array}$ & P value \\
\hline $\begin{array}{c}\text { Study } \\
(\mathrm{n}=94)\end{array}$ & 3 & 91 & $3.19 \%$ & 0.079 \\
\hline $\begin{array}{c}\text { Control } \\
(\mathrm{n}=95)\end{array}$ & 0 & 95 & $0 \%$ & $\mathrm{NS}$ \\
\hline \multicolumn{3}{|c|}{ Table 1: Comparative Incidence \& Statistical } \\
Significance of Ectopic Pregnancies \\
\hline
\end{tabular}




\begin{tabular}{|c|c|c|c|c|}
\hline & Molar & $\begin{array}{l}\text { Non- } \\
\text { Molar }\end{array}$ & $\begin{array}{c}\text { Incidence } \\
\text { (\%) }\end{array}$ & $P$ value \\
\hline $\begin{array}{c}\text { Study } \\
(\mathrm{n}=94)\end{array}$ & 2 & 92 & $2.12 \%$ & \multirow{2}{*}{$\begin{array}{c}0.554 \\
\text { NS }\end{array}$} \\
\hline $\begin{array}{l}\text { Control } \\
(n=95)\end{array}$ & 1 & 94 & $1.05 \%$ & \\
\hline & nifi & V I & $\begin{array}{l}\text { e \& Sta } \\
\text { gnancie }\end{array}$ & \\
\hline
\end{tabular}

That incidence of miscarriage/abortion (Before 28 weeks) was higher in study group (28.72\%) compared to control group $(11.57 \%)$, which is statistically significant.

\begin{tabular}{|c|c|c|c|c|}
\hline & Miscarriage & $\begin{array}{c}\text { No } \\
\text { Miscarriage }\end{array}$ & $\begin{array}{c}\text { Incidence } \\
(\%)\end{array}$ & $P$ value \\
\hline $\begin{array}{c}\text { Study } \\
(\mathrm{n}=94)\end{array}$ & 27 & 67 & $28.72 \%$ & \multirow{2}{*}{$\begin{array}{l}0.003 \\
\mathrm{~S}\end{array}$} \\
\hline $\begin{array}{l}\text { Control } \\
(n=95)\end{array}$ & 11 & 84 & $11.57 \%$ & \\
\hline \multicolumn{5}{|c|}{$\begin{array}{c}\text { Table 3: Comparative Incidence \& Statistical } \\
\text { Significance of Spontaneous Miscarriage } \\
\text { (Before } 28 \text { Weeks) }\end{array}$} \\
\hline
\end{tabular}

The incidence of pregnancies continued beyond 28 weeks was much less in study group (65.95\%) compared to control group (87.36\%).

\begin{tabular}{|c|c|c|c|c|}
\hline & Continued & $\begin{array}{c}\text { Not } \\
\text { Continued }\end{array}$ & $\begin{array}{c}\text { Incidence } \\
\text { (\%) }\end{array}$ & $\begin{array}{c}P \\
\text { value }\end{array}$ \\
\hline $\begin{array}{c}\text { Study } \\
(\mathrm{n}=94)\end{array}$ & 62 & 32 & $65.95 \%$ & \multirow{2}{*}{$\begin{array}{c}0.0004 \\
\mathrm{~S}\end{array}$} \\
\hline $\begin{array}{l}\text { Control } \\
(\mathrm{n}=95)\end{array}$ & 83 & 12 & $87.36 \%$ & \\
\hline $\begin{array}{r}\text { Tc } \\
\text { Sign }\end{array}$ & 4: $\operatorname{Com}_{l}$ & $\begin{array}{l}\text { tive Incid } \\
\text { nancies C } \\
\text { Weeks }\end{array}$ & \& Stati & $\begin{array}{l}d \\
d 28\end{array}$ \\
\hline
\end{tabular}

The incidence of APH was more than 2 times higher in study group (13.82\%) compared to control group (5.26\%) $(\mathrm{P}<0.05)$. Incidence of placenta previa was more in study group (7.44\%), compared to control group (3.15\%). Incidence of placental abruption was more in study group $(2.12 \%)$ compared to control group (0\%).

\begin{tabular}{|c|c|c|c|c|}
\hline & APH & No APH & $\begin{array}{c}\text { Incidence } \\
\text { (\%) }\end{array}$ & P value \\
\hline $\begin{array}{c}\text { Study } \\
(\mathrm{n}=94)\end{array}$ & 13 & 81 & $13.82 \%$ & \multirow{2}{*}{$\begin{array}{c}0.045 \\
\mathrm{~S}\end{array}$} \\
\cline { 1 - 4 } $\begin{array}{c}\text { Control } \\
(\mathrm{n}=95)\end{array}$ & 5 & 90 & $5.26 \%$ & \\
\cline { 1 - 3 }
\end{tabular}

Table 5: Comparative Incidence \& Statistical Significance of Antepartum Haemorrhage (APH)

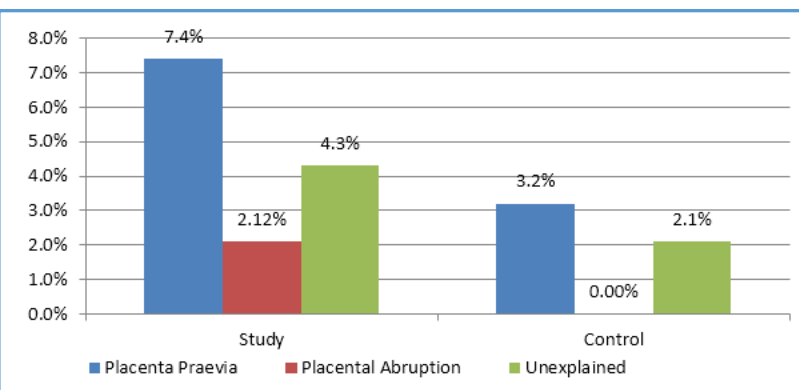

Fig. 1: Comparative incidence of different causes of antepartum haemorrhage
The incidence of preterm delivery, PROM, PPROM were higher in study group compared to control group, although they are not statistically significant.
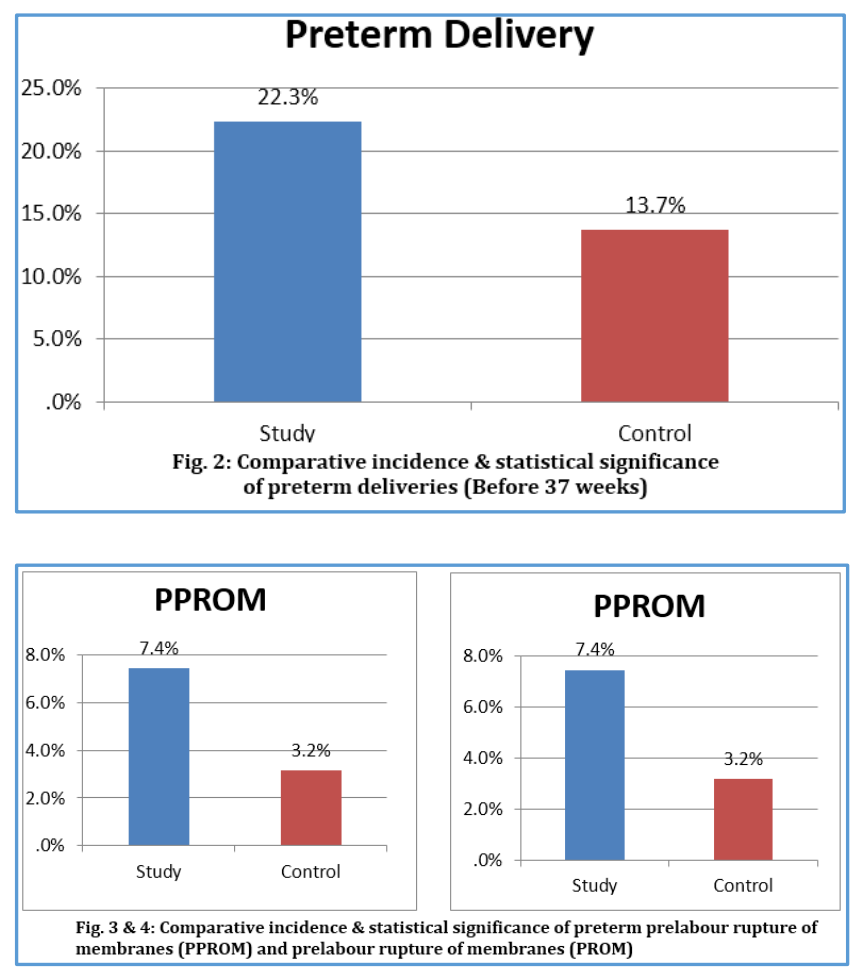

The incidence of IUGR was 2 times higher in study group (15.95\%) compared to control group (7.36\%), which is statistically significant.

\begin{tabular}{|c|c|c|c|c|}
\hline & IUGR & $\begin{array}{c}\text { No } \\
\text { IUGR }\end{array}$ & $\begin{array}{c}\text { Incidence } \\
\text { (\%) }\end{array}$ & $\begin{array}{c}\text { P } \\
\text { value }\end{array}$ \\
\hline $\begin{array}{c}\text { Study } \\
(\mathrm{n}=94)\end{array}$ & 15 & 79 & $15.95 \%$ & \multirow{2}{*}{0.046} \\
\cline { 1 - 3 } $\begin{array}{c}\text { Control } \\
(\mathrm{n}=95)\end{array}$ & 7 & 88 & $7.36 \%$ & $\mathrm{~S}$ \\
\cline { 1 - 3 } & &
\end{tabular}

Table 6: Comparative Incidence \& Statistical

Significance of Intrauterine Growth Restriction (IUGR)

The incidence of PIH was definitely more in the study group (12.76\%) compared to $7.36 \%$ in the control group. Incidence of preeclampsia was $5.31 \%$ in the study group compared to $2.10 \%$ in the control group. No case of eclampsia was found in either group. In our study vaginal deliveries were found in $41.48 \%$ of cases in study group compared to $56.84 \%$ in the control group, which is significant $(\mathrm{P}<0.05)$. Incidence of caesarean section was $13.82 \%$ in the study group compared to $11.57 \%$ in the control group.

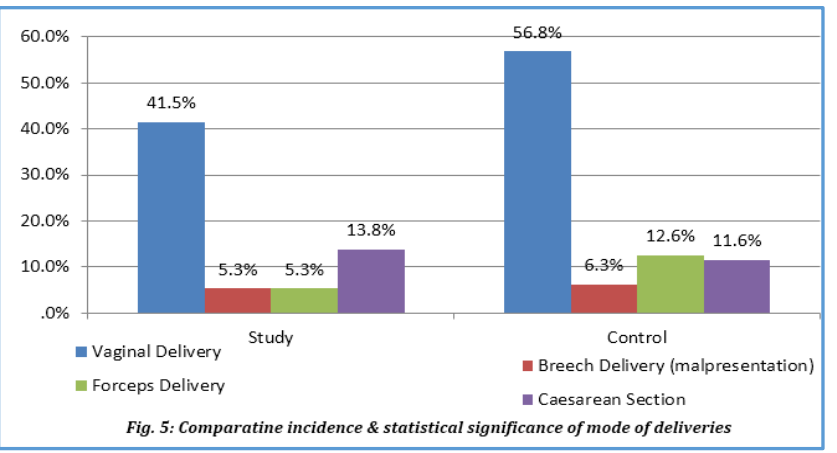


In this study, incidence of IUFD was slightly higher in study group $(3.19 \%)$ compared to control group (1.05\%). In study group (20.21\%), incidence of LBW is higher compared to control group (13.68\%). Incidence of birth asphyxia and early neonatal death in study group were not statistically significant compared to control group. No case of congenital anomaly was found in either group in our study.

\begin{tabular}{|c|c|c|c|}
\hline & $\begin{array}{c}\text { Study } \\
(\mathbf{n = 9 4 )}\end{array}$ & $\begin{array}{c}\text { Control } \\
(\mathbf{n = 9 5})\end{array}$ & P value \\
\hline IUFD & $3(3.19 \%)$ & $1(1.05 \%)$ & $0.307 \mathrm{NS}$ \\
\hline LBW & $\begin{array}{c}19 \\
(20.21 \%)\end{array}$ & $\begin{array}{c}13 \\
(13.68 \%)\end{array}$ & $0.231 \mathrm{NS}$ \\
\hline $\begin{array}{c}\text { Birth } \\
\text { Asphyxia }\end{array}$ & $\begin{array}{c}11 \\
(11.70 \%)\end{array}$ & $9(9.47 \%)$ & $0.619 \mathrm{NS}$ \\
\hline $\begin{array}{c}\text { Early } \\
\text { Neonatal } \\
\text { Death }\end{array}$ & $2(2.12 \%)$ & $1(0.05 \%)$ & $0.554 \mathrm{NS}$ \\
\hline $\begin{array}{c}\text { Congenital } \\
\text { Anomaly }\end{array}$ & NIL & NIL & NIL \\
\hline \multicolumn{2}{|c|}{$\begin{array}{c}\text { Table 7: Comparative Incidence \& Statistical } \\
\text { Significance of Foetal \& Neonatal Outcome }\end{array}$} \\
\hline \multicolumn{3}{|c|}{}
\end{tabular}

\section{DISCUSSION}

The term 'abortion/miscarriage' denotes the termination of pregnancy after implantation of blastocyst in the endometrium before the foetus has attained viability. Traditionally, the foetus is considered viable once it has attained 28 weeks of pregnancy and/or weight over 1000 gms. With advancement in neonatal care during recent years, the lower level of period of viability has been brought down. According to World Health Organization (WHO), cut-off point is 22 weeks of gestation or 500 gm weight. According to FIGO, the expulsion or extraction of foetus or embryo at less than 20 weeks or weighing less than 500 gms is called abortion/miscarriage. Now-a-days 'miscarriage' is better terminology and well accepted than the term 'abortion.'

Pregnancy failure in the first trimester is common. Indeed, it is a physiological mechanism for removing mal-developed or chromosomally abnormal embryos. Not all ova exposed to fertilization will become zygote and not all zygote will implant. Of these that implant and produce detectable amount of $\beta$-hCG (chemical pregnancy), some will abort at the time of next menstruation before the woman knows she is pregnant. Most patients have bleeding, pain or both.

Thirty percent of women in early pregnancy will experience pain or bleeding. ${ }^{6}$ Miscarriage is known to occur in $10 \%$ to $20 \%$ of pregnancies. ${ }^{7}$

Most studies estimate that $15 \%-20 \%$ of clinically recognized pregnancies end in miscarriage. ${ }^{8}$ When bleeding occurs in first trimester approximately $30 \%$ of patients have miscarriage, $10-15 \%$ has an ectopic pregnancy, approximately $0.2 \%$ have a hydration mole and approximately $5 \%$ have termination of pregnancy. The remaining $50 \%$ of pregnancies continue beyond 20 weeks. ${ }^{9}$

The first trimester miscarriage rate after confirmation of viability in the threatened miscarriage group was 9.3\%. Compared with controls women presenting with threatened miscarriage were more likely to deliver prematurely, $5.6 \%$ compared with $11.9 \%$ respectively and this was most likely to be between 34 and 37 weeks. They were also more likely to have preterm prelabour rupture of membrane, 1.9\% compared with $7 \%$ respectively. Overall, there was no difference in mean birth weight and in the incidence of other obstetric complications between the 2 groups; however, women in the threatened miscarriage group were more likely to deliver neonates between 1501 gms and 2000 gms $(p=0.04)$. Women with threatened miscarriage in the first trimester are at increased risk of premature delivery and the risk factor should be taken into consideration when deciding upon antenatal surveillance and management of their pregnancies. ${ }^{10}$

Threatened miscarriages are managed expectantly. If bleeding is slight and is not associated with pain, then the woman can be reassured that the pregnancy is likely to continue. Of all pregnancies with which bleeding occurs, more than $50 \%$ continue. $^{9}$

If bleeding occurs at 10 weeks gestation, more than $90 \%$ continue at 13 weeks gestation $99 \%$ continue. 11

If the menstrual or gestational age is greater than 6 weeks, then ultrasound may show a healthy ongoing pregnancy. In such cases, likelihood of pregnancy loss is less than $3 \%{ }^{12}$ Ultrasonogram before 6 weeks is less likely to be helpful. If the patient needs the reassurance of an ongoing pregnancy by ultrasound, then this evaluation should be undertaken after 6 weeks.

In one study, $12 \%$ of pregnancies in which bleeding occurred ended in miscarriage. Other studies reported higher rates $(\geq 16 \%) .13$, but these studies did not include women who did not know they were pregnant $(\geq 16) .{ }^{14}$ or those who did not seek medical advice about their bleeding knowing that they were pregnant (approximately 12\%).13

Although bleeding significantly decreases the chance of a normal pregnancy outcome, more than $50 \%$ of pregnancies did progress to term. The presence of cardiac activity in this population as a sign of foetal viability offered a better pregnancy prognosis. However, the predictive value of foetal cardiac activity was reduced in the presence of vaginal bleeding in an infertile population treated with routine infertility treatment. ${ }^{15}$

Obstetrical and neonatal data were analysed for pregnancy outcome in 259 deliveries complicated by first or second trimester vaginal bleeding. There was a high incidence of Low Birth Weight (LBW), low gestational age, perinatal death, asphyxia, breech delivery, placental infarcts and small for dates term infants. Foetal anomalies were slightly though not significantly increased. Combined suboptimal pregnancy outcome occurred in 29.7 percent of these deliveries compared to 15.2 percent of 25118 concurrent deliveries without reported early pregnancy bleeding ( $\mathrm{p}$ less than 0.0001 ). The combined risk remained approximately doubled even for Primigravida and for women without prior illness or pregnancy complications. The highest combined risk, 61.5 percent, was for women with at least two prior abortions, premature births or perinatal deaths and no prior term births. These findings suggest that early gestational vaginal bleeding is one predictor of suboptimal pregnancy outcome. ${ }^{16}$

The incidence of low birth weight among infants of women with bleeding in early pregnancy is 2-3 times more than in infants of women without bleeding. Preterm birth rate increases with bleeding in early pregnancy. ${ }^{17}$

The incidence of vaginal bleeding in pregnancies with Down's syndrome was about 1.7 times more than the unaffected pregnancies. ${ }^{18}$ But most of the studies concluded 
that there was no excess of congenital anomalies of the foetus after vaginal bleeding in first trimester.

Perinatal mortality rate increases in cases of mothers with history of bleeding in early pregnancy. So, suboptimal outcome should be kept in mind while continuing pregnancy complicated by vaginal bleeding in early weeks of pregnancy. ${ }^{19}$

Practically, the management of early pregnancy problems hinges around ultrasound confirmation of ongoing pregnancy. Ultrasound in a useful tool to aid decisions regarding management of abnormal pregnancy, such as ectopic pregnancy or miscarriage or others. Ultrasound examination was first adapted for obstetric use in the 1950's by Ian Donald and it has since become mainstay of early pregnancy diagnosis. It provides a safe and non-invasive diagnosis of normal and abnormal early pregnancy.

Traditionally, an early pregnancy scan was performed with transabdominal transducers; however, using this method up to $42 \%$ of women will require a vaginal scan because the bladder is not full enough or the scan is inconclusive. ${ }^{20}$

Transvaginal Scan (TVS) was introduced in the late 1980s, and it provides superior images than transabdominal scan because of close proximity of pelvic organs. Additionally, a TVS can be used at earlier gestations. ${ }^{21}$ It gives clear images and can be performed instantly, as the patient needs an empty bladder.

Transvaginal scanning obtains the clearest images in gestations less than 8 weeks, but it is important to also have facilities for abdominal scanning for the minority of women who decline a transvaginal scan. TVS is superior to abdominal scans at gestations less than 10 weeks in women with retroverted uteri or in those who are overweight. 22

Transvaginal scanning has been found to be acceptable in the early pregnancy setting in $98 \%$ of women. ${ }^{23}$ When the ultrasound identified a viable pregnancy woman can in general be reassured; of those presenting with a threatened miscarriage and a foetal heart between 6 and 14 weeks, $90 \%$ of pregnancies will continue. ${ }^{24}$

\section{CONCLUSION}

From this study, we can say bleeding pervagina in the first trimester of pregnancy should be a serious concern to the obstetrician to remain vigilant throughout the antepartum, intrapartum and postpartum period due to possibilities of various complications to mother as well as to the growing embryo or foetus.

Serial ultrasonography (TVS - preferably for early weeks of gestation) is essential to evaluate the status of pregnancy to localize the placenta, to diagnose congenital anomalies and also to monitor growth of the foetus

Thus, pregnancies with bleeding pervagina in first trimester should be counselled properly regarding the foetal and maternal complications which may arise. We the obstetricians should not treat these patients casually, because we can miss ectopic pregnancies which is a life-threatening condition.

\section{REFERENCES}

1. Weiss, Joshua L, Malone, et al. Threatened abortion: a risk factor for poor pregnancy outcome, a population-based screening study. American Journal of Obstetrics and Gynecology 2004;190(3):745-50.
2. Knudsen UB, Hansen V, Juul S, et al. Prognosis of a new pregnancy following previous spontaneous abortion. Eur J Obsatet Gynaecol Reprod Biol 1991;39(1):31-6.

3. Pouly JL, Chapron C, Manhes $\mathrm{H}$, et al. Multifunctional analysis of fertility after conservative laparoscopic treatment of ectopic pregnancy in a series of 223 patients. Fertile Steril 1991;56(3):453-60.

4. Semer DA, Macfee MS. Gestational trophoblastic disease: epidemiology. Semin Oncol 1995;22(2):109-12.

5. Ajit W, Sohinee B, Ashalatha S, et al. Obstetric outcome in women with threatened miscarriage in the first trimester. Obstetrics and Gynaecology 2006;107(3):557-62.

6. Shillito J, Walker J. Early pregnancy assessment units. Br J Hosp Med 1997;58(1):505-9.

7. Bradley E, Fairley HD. Managing miscarriage in early pregnancy assessment units. Hosp Med 1998;59(6):4516.

8. Zinaman MJ, Clegg DE, Brown CC, et al. Estimates of human fertility and pregnancy loss. Fertil Steril 1996;65(3):503-9.

9. Stabile I, Campbell S, Grudinskas JG. Ultrasonic assessment of complications during the first trimester of pregnancy. Lancet 1987;2(8570):1237-40.

10. Jemma J, Eric J. Threatened miscarriage as a predictor of obstetric outcome. Obstetrics and Gynecology 2006;107(4):845-50.

11. Pandya PP, Snijders RJ, Psara N, et al. The prevalence of non-viable pregnancy at 10-13 weeks of gestation. Ultrasound Obstet Gynaecol 1996;7(3):170-3.

12. Wilson RD, Kendrick V, Wittman BK, et al. Spontaneous abortion and pregnancy outcome after normal first trimester ultrasound examination. Obstet Gynecol 1986;67(3):352-5.

13. Everett $\mathrm{C}$. Incidence and outcome of bleeding before the $20^{\text {th }}$ week of pregnancy: prospective study from general practice. BMJ 1997;315(7099):32-4.

14. Wilcox AJ, Weinberg CR, O'Conner JF, et al. Incidence of early loss of pregnancy. N Engl J Med 1988;319:189-94.

15. Zoetania DN, Anita SP, Karachalios P, et al. Vaginal bleeding and early pregnancy outcome in an infertile population. Journal of Assisted Reproduction and Genetics 1996;13(3):212-5.

16. Funderburk SJ, Guthrie D, Meldrum D. Outcome of pregnancies complicated by early vaginal bleeding. British Journal of Obstetrics and Gynaecology 1980;87(2):100-5.

17. Silpila P, Hartikainen-Sorri AL, Oja H, et al. Perinatal outcome of pregnancies complicated by vaginal bleeding. Br J Obstet Gynaecol 1992;99(12):959-63.

18. Cuckle H, Mason G, Holding S, et al. Taking account of vaginal bleeding in screening for Down's syndrome. Br J Obstet Gynaecol 1994;101(11):948-53.

19. Vaginal bleeding in early pregnancy. $\mathrm{Br}$ Med J 1980;281(6238):470.

20. Shilito J, Walker JJ. Early pregnancy assessment units. Br J Hosp Med 1997;58(10):505-9.

21. Fossum GT, Davajan V, Kletzky OA. Early detection of pregnancy with transvaginal ultrasound. Fertile Steril 1988;49(5):788-91. 
22. Cullen MT, Green JJ, Reece ES, et al. A comparison of transvaginal and transabdominal ultrasound in visualizing the first trimester conceptus. J Ultrasound Med 1989;8(10):565-9.
23. Basama FM, Crohill F, Price A. Women's perception of transvaginal in the first trimester in an early pregnancy assessment unit. Arch Gynecol Obstet 2004;269(2):11720.

24. Fox R, Richardson JA, Sharma A. Early pregnancy assessment. Obstet Gynecol 2000;2(2):7-12. 